\title{
ACTIVE SHOOTERS — HOW CLOSE ARE THEY?
}

\author{
Marek Dabrowski ${ }^{1,2}$, Maciej Sip ${ }^{1,2}$, Dariusz Rogozinski ${ }^{2}$, Bogdan Serniak², \\ Dawid Czarny ${ }^{3}$, Tomasz Sanak ${ }^{4,5}$
}

\author{
'Department of Rescue and Disaster Medicine, Poznan University of Medical Sciences, Poland \\ ${ }^{2}$ Polish Society of Medical Simulation, Poland \\ ${ }^{3}$ Journal Club, Poznan University of Medical Sciences, Poland \\ ${ }^{4}$ Institute of Disaster Medicine and Emergency, Faculty of Anaesthesiology and Intensive Therapy, \\ Collegium Medicum, Jagiellonian University, Krakow, Poland \\ ${ }^{5}$ Department of Battlefield Medicine and Medical Simulation of Centre of Postgraduate Education, \\ Professional Development and Medical Simulation, Military Institute Warsaw, Poland
}

\begin{abstract}
Recent terrorist attacks in the United States, Canada and Western Europe have shown an increase in the incidence of "Active Shooters" [1]. These ruthless and desperate assassins usually attack urban and poorly protected areas (lack of armed protection) that are densely populated [2]. Utilizing their strength, they realize that their plan is to maximize the number of casualties, without counting on the consequences of their actions. The basis of their action may be based on extremely radical views. Frequent outcomes for active shooters include suicide during an attack $(90 \%)$ or the resolution of the threat by the authorities [3]. In response to the ever-increasing number of assassinations and the risk of such incidents in one's immediate surroundings, comprehensive education should be widely spread. Thus, it is important to promote appropriate behaviour, rules of reaction during an attack by an armed assailant, as well as cooperation with incoming service personnel. Such actions will not only help one prevent, but also allow one to prepare for such incidences.
\end{abstract}

KEY WORDS: active shooter, terrorist attack, safety, tactical medicine, run, hide, fight

Disaster Emerg Med J 2017; 2(2): 69-73

\section{WHO IS AN ACTIVE SHOOTER?}

An active shooter is a mass murderer whose goal is to generate as many casualties as possible. The target of the active shooter is typically a closed space characterized by a large concentration of potential victims [2]. This allows the attacker to kill many people in a short time-frame. An example is the action of James Holmes at a cinema in Aurora, Colorado, USA, who killed 12 people and injured 58 in under 15 minutes. In addition, Sueng-Hui killed 33 people, including himself, in less than 11 minutes.

An active shooter is usually a man $<45$ years old. Regarding school premises, the perpetrators are predominantly teenagers aged 15-19, while outside school premises the age varies between
35-44 $[2,4]$. Psychological profiles identify such attackers as emotionally unstable and acting due to political, ideological or religious causes, as well as being sometimes guided by imaginary or real motives of revenge $[1,5]$. Studies have also shown that the perpetrator usually causes self-harm (98\% of the incidents) [3]. The attacker is often solitary, isolated from society, and displays increased levels of frustration. In addition, the perpetrator is unpredictable and difficult to foresee their activities. The reasons for the actions of an active shooter may be as a result of the desire to commit suicide, or due to feelings of loneliness, anxiety or depression [6]. It is difficult to fully determine the motive behind an attack, as about $90 \%$ of active shooter incidents 
end in suicide or shooting of the perpetrator by the authorities [3].

It is certain that an active shooter does not kill for material gain, does not take hostages, does not negotiate, and whose sole purpose is to kill as many people as possible with no consequence regarding his or her actions.

Perpetrators often prepare for months in order to fulfil their plans, such as analyzing the location of the attack, evacuation routes, potential arrival times, as well as the potential population at risk. There have also been cases where the perpetrator prepared for an attack during intensive firearm training and while being member of a shooting club.

To accomplish their task, $80 \%$ of the attackers used large weapons while 75\% used multiple weapons. On average, active shooters use three weapons. Depending on the region and relevant laws, such weapons were acquired legally or through criminal activity. In addition, attackers secured a large amount of additional ammunition and explosives, which were improvised to their desired specification. They conducted attacks wearing masks, camouflage gear, while being protected by bulletproof vests (Tab. 1) [3].

\section{HOW TO BEHAVE DURING AN EVENT WITH AN ACTIVE SHOOTER?}

During an active shooter attack, the outcome of life and death of victims may be determined within seconds. This is the time when quick and rational decisions should be made. It is important to keep calm and not to panic. Although direct contact with an assassin ends in death $99.9 \%$ of the time, there was an incident where an attacker, Andreas Breivik spared the life of a Pole, Adrian Pracoń. The reason for Andreas Breivik sparing Adrian Pracoń's life stemed from Adrian Pracoń's distinctive appearance displaying "Norwegian roots". Moreover, Brevik broke the existing rules regarding active killers as he did not resist arrest and immediately put himself into the hands of police officers. As a result, the event of Andreas Breivik's attack did not lead to a mass murder.

Recommendations regarding one's reaction in the presence of an active shooter in one's area must be based on a reasonable and well-thought-out plan. In this situation, there are three possible forms of reaction:

1. Escape:

- Make sure you have a safe escape route available;

- Run as far as possible from the threat;

- Evacuate the scene regardless of whether others agree with your decision;

— Leave your belongings behind;

- Keep a phone with you;

- Help others to escape;

- Hide while bullets are being shot;

- Call the emergency services and provide information regarding the following:

- The location and number of attackers;

- A physical description of the attacker(s);

- The number and type of weapons used by the perpetrators;

- The number of potential victims at the scene of the incident.

2. Hiding:

- If evacuation is not possible, look for a place to hide;

- Do not fall into a trap that will prevent you from moving;

\section{Table 1. Active shooter incidents. Source: Own study by M. Sip, M. Dabrowski}

\begin{tabular}{|c|l|c|c|}
\hline \multicolumn{1}{|c|}{ Pear } & \multicolumn{1}{|c|}{ Place } & Deaths & Injured \\
\hline 2017 & Reia Club, Istanbul, Turkey & 39 & 69 \\
\hline 2015 & Bataclan Theater, Paris, France & 89 & 100 \\
\hline 2015 & Charlie Hebdo, Paris, France & 12 & 11 \\
\hline 2012 & Cinema, Aurora, Colorado, USA & 12 & 58 \\
\hline 2011 & Utoya Island, Oslo, Norway & 77 & 242 \\
\hline 2011 & Rio de Janeiro, Brazil & 13 & 22 \\
\hline 2011 & Tucson, Arizona, USA & 6 & 13 \\
\hline 2009 & Fort Hood, Texas, USA & 13 & 42 \\
\hline 2007 & Virginia Polytechnic Institute and State University, Virginia, USA & 33 & 23 \\
\hline 1999 & Columbine High School, Colorado, USA & 15 & 24 \\
\hline
\end{tabular}


- If you are in an office, try to lock and block the door (using heavy furniture);

- If you are in a corridor, try to get to the nearest room with a lockable door;

- Mute your phone and all sources of noise (i.e. radios);

— Turn off the lights;

- Keep silent and calm;

- Call the emergency services.

3. Fight:

- As a last resort with immediate threat to life, try to disrupt the actions of the attacker;

- Act as aggressively as possible in order to try to kill the assassin;

- Throwing objects towards the attacker, using improvised weapons;

- Scream (Tab. 2) [1, 2].

\section{HOW TO BEHAVE WHEN \\ THE EMERGENCY SERVICES ARRIVES?}

Based on the character of events involving an active shooter, one can determine their intention as an act of terror. The degree of challenge for the on-site personnel is affected by the attacker's weapons of choice (i.e. firearms and explosive charges), dynamics of the situation, and the number of casualties the attacker is planning to cause. Additionally, the time of arrival of special units (SWAT, Special Weapons and Tactics Teams) will often be dependent on their combat readiness and plan of action.

First responders are officers who first arrive on the scene of an incident [5]. They are usually of- ficers of the Police, Border Guard, Army, Military Police, or officers of other security services and institutions. The intervention of the emergency services is based on the priority of locating an active shooter and eliminating the threat posed. Execution of this task may also pose a threat to the victims of the attack. Until the perpetrator is eliminated, the victims are treated as potential assailants. Officers will check them for weapons and interrogate each subject. Evacuation will only be decided when it is safe.

The experience of previous years is confirmed by the situation in which the assassin disposes themselves of weapons, as well as camouflage clothing, and impersonates an innocent victim in order to confuse the emergency services and quickly leave the scene. During the implementation of rescue operations by armed officers, the following rules [7] should be observed:

- Do not run away and avoid sudden movements towards armed officers;

- Keep calm and follow their instructions;

- Do not make any violent movements;

- Keep your hands open, keeping them above your head without holding any objects (bags, jackets);

- Do not disobey the commands of armed officers;

- When exposed to tear gas, do not rub your eyes, and lie on the ground;

- When the order is issued, exit as quickly as possible without asking questions during the evacuation (Fig. 1-3).

Table 2. Rules of survival during active shooter or terrorist attack. Source: own study by M. Sip, M. Dabrowski, D. Rogozinski, B. Serniak

\begin{tabular}{|l|l|}
\hline \multicolumn{1}{|c|}{$10 \times$ yes } & \multicolumn{1}{|c|}{$10 \times$ no } \\
\hline Do what the attacker(s) tell you & Do not resist \\
\hline Count your breaths to help keep calm & Do not argue with the attacker \\
\hline Calm those under your care & Do not question the attacker why you were targeted \\
\hline Positive thinking regarding outcome & Do not look into the eyes of the attacker \\
\hline Mind set on survival & Do not yell \\
\hline Calmly wait for help & Do not cry \\
\hline $\begin{array}{l}\text { Ask for permission to go to the toilet, open your bag or feed an } \\
\text { infant }\end{array}$ & Do not only think of yourself \\
\hline $\begin{array}{l}\text { Use the attackers name to make them feel that you are not just } \\
\text { an object and that in fact you too are human }\end{array}$ & Do not turn your back on the attacker \\
\hline Remember as much detail as possible regarding the attacker & Do not do anything without permission \\
\hline When help arrives, wait for commands & Do not make any sudden movements \\
\hline
\end{tabular}




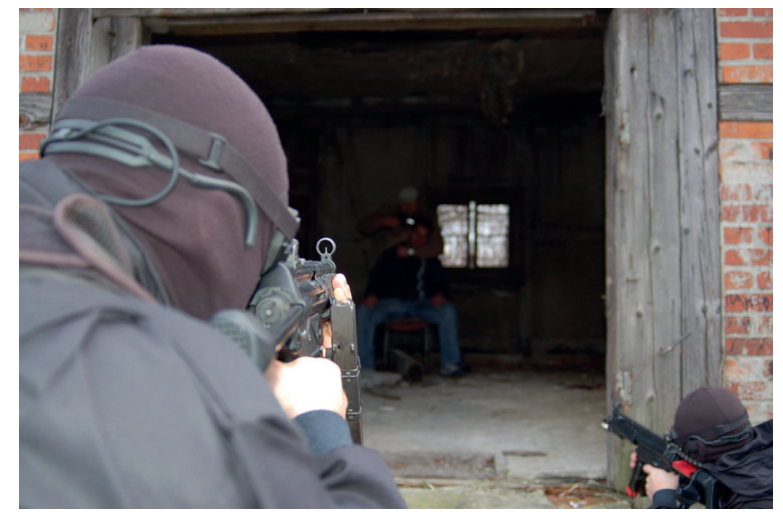

FIGURE 1. Active shooter

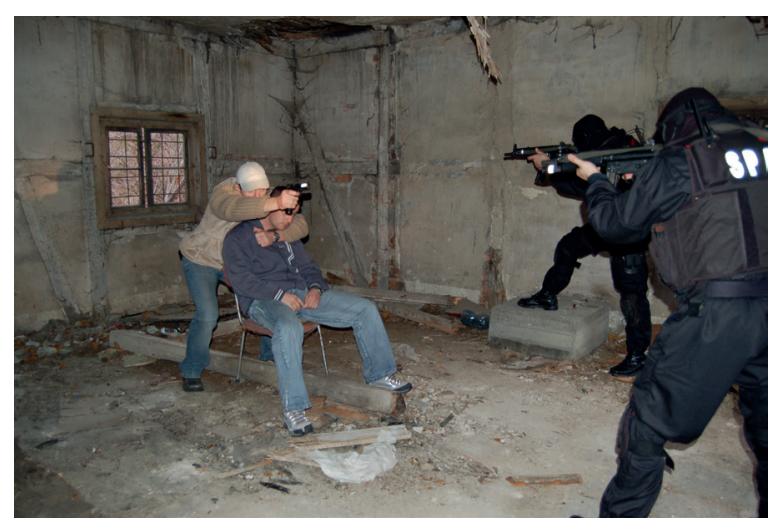

FIGURE 2. Active shooter - hostage situation

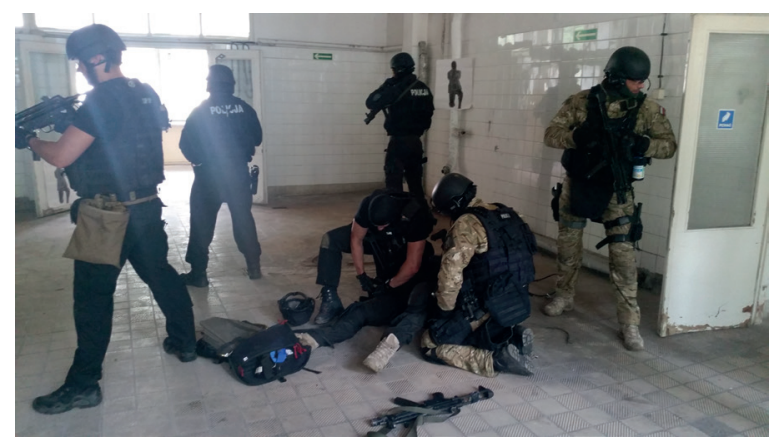

FIGURE 3. Active shooter - medicine in tactical environments

\section{PREVENTATIVE ACTION}

The recent incidence of armed robbery in urban areas leads one to believe that such incidents will be dealt with more frequently. Thus, it is important to publicize the problem. In order to prevent casualties, preventive actions should be targeted towards response training such as simulation exercises and information campaigns. Such simulation exercises should include studying the area or complex of buildings in which the exercise is located, the creation of escape procedures and specific escape routes (at least two). Creation of an informative system for alerting staff and defining their roles and responsibilities is necessary [8]. Practice is essential for uniformed officers such as police patrol and SWAT teams. This training should also include classes in the recognition of gun-shot sounds, arrows, suspicious objects (Tab. 3), and finally, learning techniques of incapacitation when in confrontation with an assassin.

Another mitigation of action that will discourage attackers from potential attacks is by providing physical and electronic security measures (armed guards, metal detection gates, monitoring). In the event of an attack, the most important thing is to reduce the perpetrator's movements, while allowing victims to escape. The time associated with the freedom of action of the attacker is associated with more victims [1]. This is difficult to achieve; the presence of safe indoor and outdoor spaces should be considered when designing the building.

Furthermore, the waiting time from being wounded to the arrival of help may be a factor when accounting for the number of deaths. Therefore, training in the scope of first aid or "Self-help" can significantly reduce the number of deaths until the arrival of the emergency services [9-13]. According to the principles of development and propagation of PAD (Publish Access Defibrillation) programs, it is important to emphasize the "Bleeding Control First Programs" (BCF). This may lead one to consider the importance of providing First Aid Kits with many dressings and tourniquets, bandages, hemostatic agents, and even some needles for tension pneumothorax decompressions [13].

\section{CONCLUSION}

When analyzing violence involving active shooters in recent years, there has been a noticeable increase in the incidence of attacks. It should be asked whether there is a risk of the occurrence of this type of event in Poland and whether citizens know how to behave

Table 3. Reaction to suspicious objects.
Source: Own study by T. Sanak, M. Dabrowski
\begin{tabular}{|l|}
\multicolumn{1}{|c|}{ How to respond to suspicious objects } \\
\hline Do not touch the object \\
\hline Do not move the object \\
\hline Get away as far as possible from the object \\
\hline Warn others regarding the object \\
\hline Call the emergency services or call 112 \\
\hline
\end{tabular}


in such circumstances. The current geopolitical situation in Europe and the increase in the occurrence of information about such events is a clear indicator to not downplay this problem but instead find innovative solutions. Information campaigns in the media, schools and academic campuses, and simulated scenarios involving active shooters are one of the preparatory approaches to such situations $[8,11]$. The aims of high quality training are to increase skills and learn proper attitudes towards hazards. The dissemination of leaflets in public places with information regarding terrorist attack is another step in preparing the public for dangerous situations. These actions can make the public aware of the event they may be dealing with and, above all, show what rules to follow in order to increase their chances of survival.

Conflict of interest: None declared.

\section{REFERENCES}

1. Active Shooter guidelines for places of mass gathering, Australia-New Zealand Counter-Terrorism Committee. April 2015.

2. Kelly RW. Active Shooter Recommendations and Analisis for Risk Mitigation. New York City Police Department, 2012.

3. French G. Single Person Response To Active Shooter? http:// churchsecuritymember.com/single-person-response-to-active-shooter/ (15.03.2017).

4. MSA Worldview, Special Analysis: The Active Shooter Threat 2012.
5. Hołyst B, Staniaszek M, Binczycka-Anholcer M. Samobójstwo. Wydawnictwo Polskie Towarzystwo Higieny Psychicznej, Warszawa 2002: 70.

6. Małysa T. Konfrontacja z aktywnym strzelcem. e-terroryzm. pl. Internetowy biuletyn Centrum Studiów nad Terroryzmem i kwartalnika e-studia nad Bezpieczeństwem i Terroryzmem 2012; 7. https://www.google.pl/url?sa $=t \& r c t=j \& q=\& e s r c=s \&$ source $=$ web\&cd $=1 \&$ ved $=0$ ahUKEwjp1Zv90vHTAhVjYZoKHcJiDOwQFggiMAA\&url=http $\% 3 A \% 2 F \% 2 F e-t e r r o r y z m . p l \% 2 F \% 3 F-$ wpdmact\%3Dprocess\%26did\%3DNy5ob3RsaW5r\&usg=AFQjCNEdDwsKOfrlchtL5_Av7Db9TjUSw\&cad=rja (15.03.2017).

7. Active shooter how to respond, U.S. Department of Homeland Security. https://www.dhs.gov/xlibrary/assets/active_shooter_booklet. pdf (15.03.2017)

8. Kelly , Kenneth T, Ed D. Campus readiness for dealing with an active shooter. California State University, Long Beach. 2015; 131: 3712515.

9. Osborne J, Capellan J. Examining active shooter events through the rational choice perspective and crime script analysis. Security Journal. 2015, doi: 10.1057/sj.2015.12.

10. Improving Active Shooter/ Hostile Event Response, Best Practices and Recommendations for Integrating Law Enforcement, Fire and EMS, A Raport Compiled By The Inter Agency Board. September 2015.

11. Butler FK. Two Decades of Saving Lives on the Battlefield: Tactical Combat Casualty Care Turns 20. Mil Med. 2017; 182(3): e1563-e1568, doi: 10.7205/MILMED-D-16-00214, indexed in Pubmed: 28290925.

12. Wands B. Guest Editorial: Active Shooter: Are We Complacent? AANA J. 2016; 84(6): 388-390, indexed in Pubmed: 28235168.

13. Sanak T, Dabrowski M, Kominek $P$, et al. The idea of the rescue task force for Emergency Medical Services Teams: The future or the present urgent to implement? Emerg Med Serv (Aluna). 2016; 4: 263-268. 